\title{
SMALLER AND BETTER: The University of Michigan Experience
}

\author{
Gerlinda S. Melchiori
}

This paper discusses several hierarchical and sequential reduction options, including Balderston's budgetary strategies and this author's curricular change options. The latter are based on data gathered in a $1979-80$ survey of 46 states on patterns of program reduction. Having introduced various reduction categories, the paper then focuses on the institutional shrinkage process currently being implemented at the University of Michigan. Four specific strategies are being discussed: (1) across-the-board cuts, (2) reduction of nonacademic programs; (3) long-range faculty reduction procedures, and (4) program discontinuance. A host of potential problems regarding the elimination of academic programs is described. The paper concludes by providing several general recommendations for institutional shrinkage procedures.

Much has been written about retrenchment. Case studies and surveys of both institutional and state level processes and strategies have burgeoned. Paradigms and theoretical frameworks analyzing the characteristics and radius of impact along the lines of hierarchical or sequential parameters have been developed (Cheit, 1971; Balderston, 1974). Cheit's survey identified five main (sequential) categories of responses: postponing, belt-tightening, cutting and reallocating, scrambling for new funds, and planning and worrying. Balderston, dealing mainly in terms of budgetary issues, mentioned four basic strategies: adjusting budgetary standards (raising student/faculty ratios, for instance), proportioning budget cuts, decentralizing revenue and expenditure control ("every tub on its own bottom"), and differentiating budget cuts according to selective priorities.

This author's 1979 survey focused on patterns of program reduction. With 46 states participating, a comprehensive data base was established regarding the range of program change options available, the frequency of their use, as well as

Presented at the Twenty-First Annual Forum of The Association for Institutional Research. Minneapolis, May 1981 .

Gerlinda S. Melchiori. The University of Michigan 
their specific attributes (Melchiori, 1980). The data on reduction options were assembled along the lines of the co-called Hirschman model and are presented in Figure 1.

In his book on decline in firms and organizations, Hirschman (1970) proposed two basic options, Voice and Exit. Voice can be defined as an attempt to, first, identify the causes responsible for the decline of a product or a program, and, subsequently, propose (or voice) mechanisms for improving its marketability if an analysis shows that it warrants continuation. Exit, on the other hand, refers to the elimination of a product or program if the review indicates that it is no longer viable, compatible, or essential. It is important that considerations not only focus on these two poles but also on the interplay between them: testing the elasticity between retention and extinction means to consider options and develop innovative alternatives. Applying this model to the above-mentioned data on patterns of program reduction, one finds that the majority of options lie in the gray area between Voice and Exit.

Arranged in a continuum, the four categories are: (1) Continuation, (2) Modification, (3) Merger, and (4) Termination. As for the first category, Continuation, a program may be continued "as is" or placed on implicit or explicit probation. Two variations are pertinent: contingent continuation, which supports continuation pending the fulfillment of specifically stated conditions, e.g., securing funds or attaining accreditation; and conditional continuation, which implies that a program is placed on probation for a stated period of time. Conditions may indicate that it will be phased out unless more students are attracted or the quality of faculty is upgraded.

The second category, Modification, contains a variety of options that are designed to explore the elasticity of a program's potential for change if the initial agreement is reached that it is worthwhile retaining albeit with fewer resources. Several change options are noted in Table I.

Moving even closer to Exit, Merger also tests the flexibility of a particular program. A merger decision signals that retention is only feasible if major adjustments are made, such as pooling resources or realigning programs. The determinants for selecting a specific merger variation are directly related to the weaknesses of the program, such as a declining student pool, high equipment, computer, or library costs, changes in the discipline and marketplace, and so on.

The fourth category, Termination, leaves behind the area of exploring options and enters a less fluid arena. Although any of the previous three categories may eventually include program discontinuance, this category states such intents much more bluntly. The term itself is ambiguous as no uniform criteria are used in defining it. Research indicates that, typically, closure activities entail either the elimination of specific degrees within a department or the discontinuance of programs whose faculty and students already have dwindled away. The elimination of academic departments and entire colleges is occurring on a minimal level. 


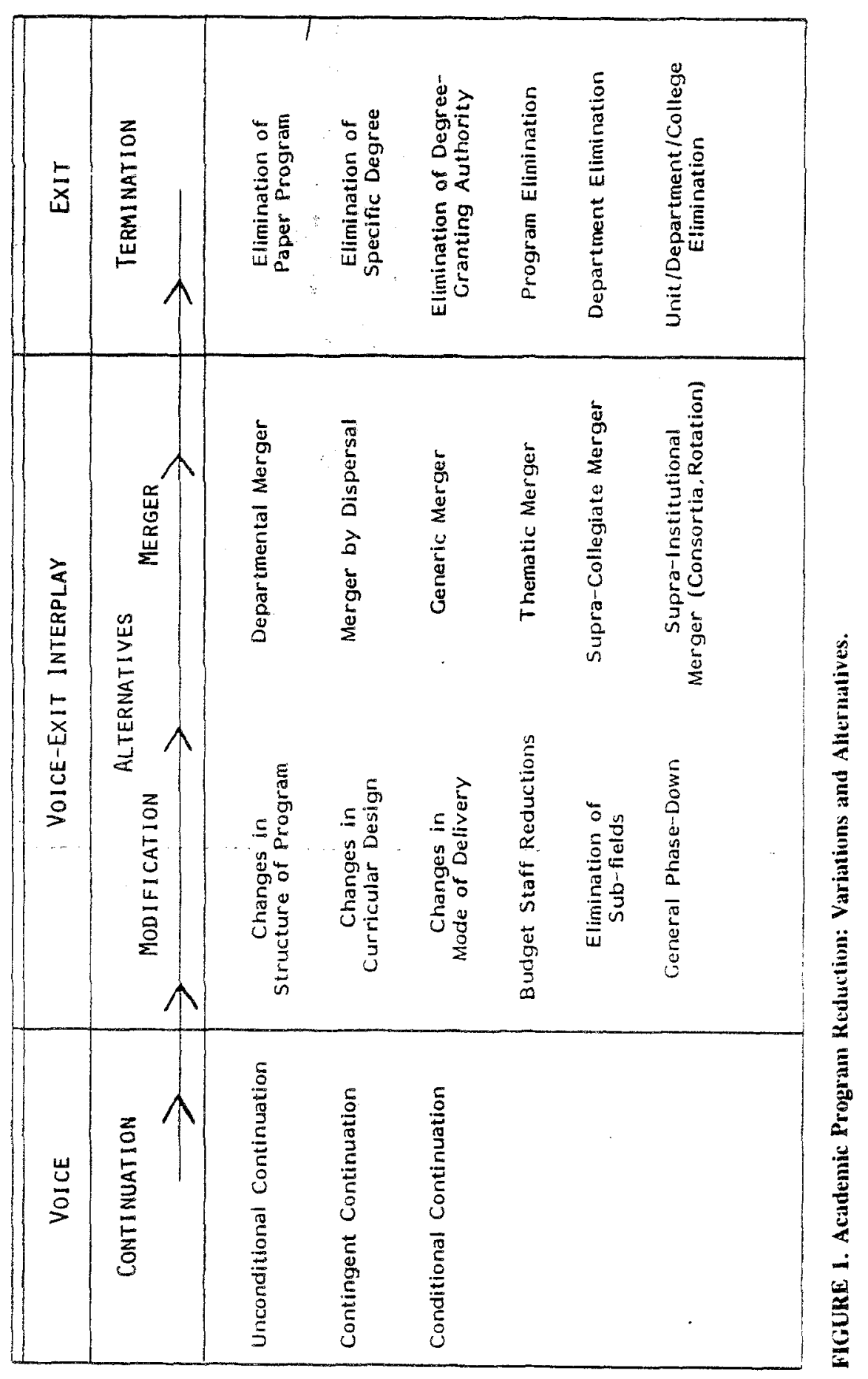


Having introduced various budgetary and programmatic decision categories, it is appropriate to turn to the case at hand and see what combination of strategies were chosen at the University of Michigan to induce reductions. A large, public institution, $\mathrm{U}-\mathrm{M}$ is recognized for its excellence in research and teaching. Operating under an independent charter granted at the state's constitutional convention in 1850, the school has enjoyed a high degree of autonomy from external interference and control. The University is noted for its decentralized decisionmaking process and practice of faculty governance.

Much has been written recently about the economic conditions of various midwestern states. In Michigan in particular, the decline of the auto industry, the rise in oil costs, an unemployment rate twice as high as the national average, as well as an increase in emigration of residents have led to a severe reduction in state revenues. Salaries in many sectors of the work force have been rolled back, and market behavior indicated that the population was in a no-nonsense mood. In 1980 , state appropriations for higher education reflected an actual budget reduction. In view of the fact that shortfalls were predicted to continue for several years, the decision was made at $U-M$ to explore a wider range of reduction options than had been the case in previous years.

Research on organizational change (Melchiori, 1981) identified many reasons why change (e.g., reductions) is difficult to implement. DeLeon (1978) lists institutional conservatism, legal obstacles, high start-up costs, and the formation of anti-termination coalitions as barriers to change. Bardach (1976), in discussing the political undercurrents of termination processes, adds to this list the lack of appropriate incentive structures, the fear of the uncertain, and the expectation of "entitlement" - to a program, tenure, job security. Behn (1978) and Cameron (1978) see the best course of action in taking advantage of ideological shiftssuch as growth to nongrowth or liberal to conservative needs-to demonstrate harm if no change (reduction) occurs. Clearly, the climate in Michigan and within the University was conducive to accepting major changes. The decision was made to initiate a gradual institutional shrinkage process. "Smaller and Better' became the motto, reflecting the intent to reduce the scope of the University's activities, staff, and budget at the expense of weaker faculty and nonpriority programs. "Smaller" may mean fewer students in some units, fewer faculty, staff, and administrators, fewer courses, a restructured curriculum, or a streamlined administrative apparatus. "Better" means, it is hoped, that a reordering of priorities will have the effect of affording better General Fund support for the remaining programs (presidential speech).

How does an institution decide how to become smaller and better? In other words, which of the aforementioned budgetary and curricular reduction options should be selected? During previous years, many of Cheit's and Balderston's suggestions had been implemented to varying degrees, and the pursuit of further reductions via proportioned and/or differential cuts in specific account 
categories-such as travel, equipment, new hires-became a less desirable option if the goal to become smaller and better was to be taken seriously. Thus some of the more dramatic steps mentioned in Figure 1, such as program and departmental discontinuance, were now being considered. Recognizing that adversarial positions on the part of faculty vis-à-vis the administration would not be in the best interest of the institution and its constituencies, both faculty and administrators felt that it was necessary to first establish reduction guidelines and goals. The following parameters for the shrinkage process evolved:

1. The concept of "shared poverty" (equal salary reduction, enforced unpaid holidays, etc.) was not considered to be a viable option for a competitive university.

2. The continued delay in acquiring new equipment and renovating existing facilities was not considered healthy as it may lead to the "save now-pay later" syndrome.

3. The reduction of top salaries was not supported on grounds that the institution may lose its bargaining power with peer institutions for the best faculty.

4. The issue of tenure as a general principle was not to be questioned.

5. Any personnel shrinkage was not to be achieved at the disproportionate expense of junior faculty or affirmative action.

6. Enrollment was to be assumed to remain constant (at least initially).

7. The process of reducing the size of the University was to be carried out with the active participation of the faculty.

The main goals for the institution were, first, to cope with the immediate impact of the recent reduction in state appropriations; second, to rebuild some of the teaching and research strengths lost during previous years through lack of funds to maintain an exit-new hires staff equilibrium; third, to regain the flexibility the University had lost because of the cumulative impact of successive annual shortfalls and inflation. This flexibility, it was argued, is necessary for the institution to be able to respond to new challenges, develop new programs, hire top faculty, pursue vital research, and acquire new equipment.

With parameters and general goals in place, the decision was made to pursue the following multilevel activities:

Strategies for ShortRange Reductions

1. Across-the-board reductions level: all

2. Differential reduction in nonacademic units level: central, college
Strategies for Medium - and

Long-Range Reductions

3. Long-range faculty reduction planning level: college, department, program

4. Department or program discontinuance level: college. department, program 


\section{ACROSS-THE-BOARD REDUCTIONS}

During the summer of 1980 it became increasingly clear that state appropriations for 1980-81 would fall considerably short of previous years. By fall the state was operating under an Executive Order, and indications were that higher education in Michigan would have to operate with an actual decline in state appropriations. Central administration was enforcing contingency planning throughout the University. Schools and colleges were asked to submit plans indicating how they would cope with General Fund reductions of 1 to 6 percent. Clearty, in a highly labor-intensive economy such budget reductions can only occur in the few remaining flexible dollar categories such as the pools of money set aside for new hires, equipment, and miscellaneous-including travel funds, TA positions, summer course monies-in other words funds that already had been raided for some time. The contingency plans once again revealed that across-the-board cuts, particularly if continued into the near future, would gradually erode the strength and vitality of the University. Predictions convinced executive officers that, in addition to across-the-board cuts and expenditure reductions for 1980-81, other ways must be found to enable the University to cope with the economic predictions for the next several years. Varying in severity and lead-time, the following three strategies were intended to address the longerrange impacts of the economic situation.

\section{REDUCTION OF NONACADEMIC PROGRAMS}

The second aspect of the plan was one of selectively reducing nonacademic units that are under the direct control of central administration. Academic Affairs staff reviewed those units and proposed to the vice-president and the Committee for Budget Administration (CBA) dollar amounts to be cut. Need, cost, and centrality to the University were important criteria. Four units were identified by the $\mathrm{CBA}$ for immediate review, and several others were earmarked for later evaluations. It is of interest to note that the subsequently appointed review committees were not charged to review these units, rather their mandate was to evaluate the impact of the suggested cutbacks. In two cases the reviews concurred with the originally proposed degrees of reduction. Recommendation for the third unit was well below the initial proposal, and in the fourth case the conclusion was to totally eliminate the unit rather than to retain a fraction as suggested. In addition, various alternatives were suggested for how to supplement the units' budgets by charging fees and increasing user charges. Despite the fact that ample press coverage occurred and that the final recommendations would directly or indirectly affect many units and people on campus, relatively little protest occurred. Several reasons come to mind. First, the multiplicity of reviews may have prevented people from rallying to one particular focal point. 
Second, these units are not tenure-housing and they do not have organizational mechanisms through which systematic coalitions could be formed. Thus, constituencies called upon for defense may have been less powerful. At the time of writing this article, indications are that these reductions will be implemented shortly, resulting in personnel reorganization, some layoffs, and an overall saving of several million dollars.

\section{LONG-RANGE FACULTY REDUCTION PROCEDURES}

Although drastic reductions and potential discontinuances tend to generate tremendous interest in the press, a systematic plan to induce faculty shrinkage is potentially much more dramatic, generating intense discussions and unleashing dynamics on the departmental and program level. Clearly, the overall goal for this plan is to put curricular goals into sharper focus, to eliminate weak or unessential fields and staff and thus enhance the quality of the University.

The purpose of a long-range faculty reduction plan is that in spite of General Fund shortfalls, some aspects of the academic curriculum receive additional attention.

Working out the details of implementing an overall shrinkage plan were left up to the individual colleges. Procedures depended upon such parameters as the internal organizational structure, estabiished patterns of facuity participation in the decision-making process, as well as specific dynamics of the situation. Perhaps the most systematic and publicized process commenced in the College of Literature, Science and the Arts, where department heads were asked to submit plans outlining how they propose to shrink over the next three to five years. Several of the general directives provided by the administration are worth noting.

1. The primary intent of this plan is to induce constructive curricular planning: to weigh curricular core needs against more esoteric addenda, to determine cost/ benefit factors regarding programs and subfields, and to evaluate the future of these specific components in light of current staffing realities.

2. Shrinkage is to be conceived of and measured in terms of faculty FTE father than dollars. Two reasons were central to this decision. First, budgets are subject to various kinds of changes that would make long-range planning difficult-such as inflation, faculty leaves and sabbaticals, research grant support, and joint appointment shifts. The second reason, even more important, was to reduce the temptation and possibilities of implementing cuts via budgetary measures such as reducing travel accounts, support staff, or equipment funds. In terms of faculty FTE, the goal is to shrink by up to 10 percent over the next three to five years.

3. Untenured faculty are not to be considered the primary prey in the shrinkage process. Also, recent affirmative action gains and future goals are supposed to be upheld. Regarding new positions, departments were asked to scrutinize and evaluate their faculty position needs within the context of longer-range depart- 
mental plans rather than to approach the request from the standpoint of replacing a particular person.

From the very beginning it was clear that such a comprehensive plan could only succeed if buttressed by an effective incentive structure. The following incentives are being considered and/or are already in use:

1. Departmental planners are encouraged to assume that reducing faculty does not necessarily mean that the budget lines are lost to the unit; some may in fact be traded to fill areas of growing demand.

2. Retirement incentives are being developed which would allow a person to retire before the age of 70 without the loss of either regular salary or full TIAA/CREF benefits.

3. Chairpersons are urged to look upon the annual salary program as a meritorious reward system and stretch the "institutional average" from zero to whatever seems appropriate or possible at the other end of the scale.

4. A research incentive program was developed to suppiement prestigious fellowship stipends with additional funds. Because such awards are typically below regular salary levels, faculty have sometimes declined to accept them. The supplement is designed to enhance their attactiveness, increase research possibilities, and contribute to raising faculty morale.

5. The mortgaging of future retirements (that is the premature filling of positions which are expected to become vacant due to retirement at a specific date) is of course a very realistic and widely encouraged method. However. chairpersons are being discouraged from using it too extensively and too prematurely-and thereby narrowing their options. and decreasing their degrees of freedom for the future.

It is far too early to speculate about the potential impact and success of this shrinkage approach. So far, departmental plans have been submitted and it is conceivable that the projected facuity flow could be simulated and analyzed in light of potential policy changes regarding hiring and promoting patterns. It may be quite difficult, if not impossible, to identify specific annual reduction goals in terms of numbers and dollars which in turn interface with the annual budget cycle and position request process. In time, other problems may arise by, for instance, developing memoranda of understanding that are binding beyond the specific actors involved at this juncture. Finally, the unresolved and untested nature of tenure and what it means in a declining market will remain a variable and an ever-present concern.

\section{DISCONTINUANCE OF ACADEMIC PROGRAMS}

None of the aforementioned strategies aimed at the more crucial issue of taking 
a serious look at the overall curriculum and the priorities and values it reflects in light of the fiscal predictions for the state and academic needs in general. To become smaller and better may require that curricular offerings and staff be evaluated with the goal to identify and possibly discontinue weak, less essential, or less cost-effective academic departments and/or programs.

Several years ago the University intended to eliminate two programs, a process which resulted in the dispersal of one unit and the reclassification from department to program status for the other. While the final chapter on the effectiveness of these measures still needs to be written, the efforts did lead to the development of a set of guidelines to be applied to future termination cases. In October 1979, the Regents approved Discontinuance Guidelines for Academic Programs that outline the kind of process to be followed, describe the role of the faculty, and mention the criteria to be taken into account, namely: (1) centrality of the unit to the curriculum, (2) quality of faculty, (3) student demand and state needs, (4) cost-benefit factors, and (5)facuity deployment possibilities. It is important to note that the guidelines leave the definition of what constitutes a program to the discretion of the individual deans. Except for the final decision-making stages, the locus of review activities rests with the respective college administrations.

In the fall of 1980, various schools through their deans and executive committees announced that some academic departments would be reviewed for potential discontinuance. Based on both the guidelines and previous program evaluations, the potential discontinuance process follows three steps: the college makes the initial selections, peer and external reviews follow, and then the recommendation is forwarded to the Vice-President and the Board of Regents. Although there is no room here to discuss the procedures in detail, it seems worthwhile to share some of the main problems and dilemmas encountered. The following comments are based on the attempt to close the Department of Geography.

\section{Participation of the University Faculty}

Literature in organizational theory has suggested that the implementation of retrenchment contributes to centralization and more authoritative methods of governance (Riley and Baldridge, 1977; Cohen and March, 1974). Experiences at the Univesity of Michigan have shown that faculty (and students), although steeped in collegial mode of governance, found it difficult to generate objections on substantive grounds, in part because of lack of overall information. Discussions inevitably seemed to focus on frocedural matters such as the legitimacy of a particular criterion or specific data rather than on the economic, curricular, and qualitative issues at hand. Realistic counterproposals were rarely voiced, a situation which may lead to the impression that, ultimately, "tough" decisions cannot be made through democratic processes including the total faculty and consequently must be handled through representation. 


\section{Consultation with the Department}

The program discontinuance guidelines mandate that a department be consulted before the comprehensive review and decision-making process begins. It was found that this requirement cannot be fulfilled to everybody's satisfaction. It seems resonable to assume that no unit would be able to assist constructively and objectively in a process that might lead to its demise. Particularly difficuit is the requirement to allow for early consultation. On the one hand, once a target has been identified, the point of early consultation has passed. On the other hand, fairly complete data need to be assembled before an initial decision "to open proceedings" can be made and be announced. To this day, the following questions remain unanswered: When is early consultation supposed to take place? And how can it take place in a both constructive and realistic manner?

\section{The Dilemma of Decentralization}

Throughout the termination process the argument was made that the specific department is not the weakest and that, universitywide, many less qualified units enjoy peaceful existence. Clearly, in a highly decentralized system there are neither intellectual measures nor organizational mechanisms to conduct supracollegiate comparisons regarding raison d'être and quality of units. Autonomy, in this case, shows its less desirable attributes.

\section{Legitimacy of Review Team and Data}

It was found that the good intentions prescribed in the guidelines for conducting peer reviews were difficult if not impossible to realize. Willingness to serve on a particular review committee automatically put these committee members in an adversarial position vis-à-vis the faculty under review as well as those who rally to the support of their beleaguered colleagues. It seems as though even the most thorough and objective members of a review team find themselves labeled adversaries if not henchmen. The same can be said about the data used. Comments that certain issues are unfair, irrelevant, incorrect, or biased seem to be part of the process.

\section{The Department on Hand and the Discipline It Represents}

Experiences nationwide have indicated that the formation of antitermination forces can assume powerful dimensions. While this can happen in terms of outright verbal protests or marches, a more subtle version is just as difficult to deal with. The reference here is to people outside the University who infer that a particular discontinuance means nothing short of passing judgment on the legiti- 
macy of the discipline per se. Obviously, the extent to which such a spill-over effect occurs is directly related to the national standing and prestige of an institution, an influence a university "normally" would not want to deny.

\section{Making a Case for Discontinuance}

Yet another problem encountered is the issue of confidentiality and sensitivity of personnel information. Once again, those involved are caught in a dilemma. On the one hand, fellow faculty, students, and the community-at-large need to be convinced that measurable deficiencies exist, yet this has to be accomplished without "washing the laundry" of the affected faculty in public. The result is that public reports will be less convincing in their rationale for drastic action.

\section{Criteria for Discontinuance}

Recent experiences once again pointed out that the rationale for or against discontinuing a program or department is a rather unsettled issue. The main cause of disagreement seems to be over the relative importance of quality vis-àvis centrality of the discipline. We can illustrate how the interplay between these two criteria can cloud the decision-making process thus:

$\begin{array}{lcc}\text { Quality } & \text { Centrality } & \text { Decision } \\ \text { high } & \text { high } & \text { Continuation } \\ \text { high } & \text { low } & ? \\ \text { low } & \text { high } & ? \\ \text { low } & \text { low } & \text { Discontinuation }\end{array}$

If one is to attach prima causa status to quality one could argue that superior quality may result in more centrality; low quality, even in a typically central discipline, may cause a move away from centrality. Conversely, if centrality is one's main concern, low quality should be dealt with by assisting the unit in attaining that status by weeding out weak faculty and/or by invigorating the unit with new blood and resources. The financial side of this argument becomes secondary in that centrality in the intellectual marketplace would seem to imply a certain justification for securing enough resources. But intellectual difficulties rest not only in determining the relative priorities of these two criteria but also in defining and measuring the concept of centrality itself. Within the galaxy of offerings, how does one determine the degree of importance of any one discipline? Should it be placed by an ideal perception, and whose? Or should it be placed on the basis of demand as demonstrated by some measurable criteria? (For further insights on this issue, see Kotler and Murphy (1981), in which the 
authors describe an academic portfolio evaluation tool whose primary evaluation dimensions are centrality and quality.)

\section{Equity in the Discontinuance Process}

Termination cases over the past decade have indicated that the larger the unit and the more national resistance the discipline can generate, the more difficult it is to pursue reductions. The sheer force of disciplines such as nursing, English, or history seems to protect weak subfields within it. Conversely, this would indicate that small departments and weaker disciplines are more vulnerable to be considered for closure. Evaluating the options, solutions need to be sought that allow for equity and efficiency. In the geography case, the review team tried to accommodate this problem by proposing consideration of two scenarios: total departmental discontinuance, or partial discontinuance, that is, discontinuing program(s) within the department. Although at first glance the former seems to be the more drastic of the two, the latter, in fact, is potentially much more radical in that it allows for the elimination of weak fields in otherwise strong and central departments, as well as for the retention of strong parts in otherwise weak departments. One of its major handicaps is that unless it is initiated by the departments themselves, it may be viewed as a witch hunt aimed at selected individuals. For this reason, and because of other potentials for misuse, partial discontinuance remained an untested recommendation. The final recommendation for geography was departmental discontinuance.

\section{CONCLUSIONS AND RECOMMENDATIONS}

The foregoing was a description of how one university decided to choose from the range of budgetary and programmatic options mentioned earlier. Deliberations had led to the decision that further belt-tightening and deferring tactics were neither enough nor healthy. Thus more radical changes, basically highly differential decisions, were initiated. Pursuing such degrees of change causes stress, critique, and anxiety on all levels of the institution. On the other hand, it should be noted that it was nonetheless an orderly process that allowed for voicing discontent and discussing alternatives. In Balderston's terminology, the process was not one of managing survival, but rather one of seeking new stability while maintaining, if not improving, excellence.

It is still too early to evaluate the short-range outcomes of these attempts in terms of dollars and positions saved, much less the long-range outcomes in terms of maintaining quality and developing flexibility, but it may not be too early at this juncture to share a few suggestions with the higher education community.

The first recommendation is not to overestimate the utility of any guidelines. The newly developed Program Discontinuance Guidelines, approved by the Re- 
gents, played a useful role in serving sometimes as a point of reference and sometimes as a scapegoat. However; one of the goals of these guidelines was to guarantee an orderly method to facilitate faculty and student input. Experience has shown that since any process operating under these guidelines will ultimately be resolved by the Regents, the locus of decisionmaking is quite removed from the place of impact and thus may in fact work counter to faculty participation. Similarly, operating under these guidelines will inevitably mean performing in the public eye. There is less room for bargaining behind closed doors, making concessions, or planning for inconspicuous phase-outs, strategies that certainly have merit in some instances.

The second recommendation is to face the fact that there are definite limits to faculty and student participation in an institutional process as comprehensive as this one. Clearly, the collective faculty cannot discuss the pros and cons of discontinuing a department or the quality of individuals, much less resolve the related problems. The same can be said about student participation. The size of the institution and the complexity of its various budgets and existing commitments limit insight and thus the utility of input. Another factor is the rapidity with which some of these decisions need to be made to respond to unexpected shortfalls. Although ample provisions for participation ought to be built into the process, it is necessary to draw lines between advisory capacities on the part of faculty and student and decision-making powers on the part of their representatives.

The third recommendation is to evaluate the role of institutional research offices in the curricular change process. Experience has shown that validity of the data gathered and compared is directly related to who provided it and whether that unit or person is seen-as an adversary or protagonist, as "administration" or "faculty." In the future, rather than having the administration gathering initial information, the affected department gathering "counter" information, and the review committee collecting yet another bulk of data, one might consider delegating the entire function to the institutional research office. This would require a fairly good consensus as to what criteria should be taken into account and how much comparative data are needed and useful. One may be able to avoid criticisms regarding the lack of objectivity of information by having the data collected by what could be called a neutral third party. Also, this method would allow for some consistency regarding the release of background material to the public and the press.

The fourth recommendation is not to open too many "cans of worms" during the process. Experience has shown that one particular activity or intent, perhaps the least popular one, will cause many skeletons or unresolved issues to emerge, for example: the extent of student participation, the relative power of small versus large departments, the extent of faculty governance in times of retrenchment, the untested status of tenure, or the lingering ambiguity regarding the 
makeup of the curriculum and the priorities and values of higher education in general. One is reminded of Cohen and March's garbage can process, a model that reflects the fact that organizational phenomena normally regarded as isolated and pathological begin to emerge if preconditions for more normal and rational process models are no longer present (Cohen and March, 1974, p. 91). The difficulty is that one cannot, in most instances, follow their advice and wait until these issues have found a new nexus around which to evolve and then quietly move ahead and decide upon the actual issue at hand.

The final recommendation concerns an issue that has remained unmentioned. throughout this paper, namely stress. Much has been written about organizational stress, often in a seemingly sterile, detached, and "measurable' manner. Experiences here indicate that there are pricetags all along the path: loss of friendships, even positions, shifts in power, resignations, stigmas, loss of influence on the part of some and gains on the part of others. This recommendation is simply to keep in mind that, really, there is no such thing as institutional stress; it is all human.

\section{ACKNOWLEDGMENTS}

This research was supported in part by the Exonn Education Foundation.

\section{REFERENCES}

Balderston, F. E. Managing today's university. San Francisco: Jossey-Bass, 1974.

Bardach, E. Policy termination as a political process. Policy Sciences, 1976, 7. 123-131. (Amsterdam; Elsevier Scientific Publishing Company).

Behn, R. D. How to terminate a public policy: a dozen hints for the would-be terminator. Policy Analysis, 1978, 4.

Cameron, J. J. Ideology and policy termination: reconstructing California's mentai health system. In J. May and A. Wildavsky (Eds.), The policy cycle in politics and public polict. Beverly Hills: Sage, 1978.

Cheit, E. F. The new depression in higher education. New York: Carnegie Commission, McGraw-Hill, 1971.

Cohen, M. D., and March, J. G. Leadership and ambiguity. New York: McGraw-Hill. 1974.

Davis, C. K., and Dougherty, E. A. Program discontinuance: its mele in strategies of resource allocation and planning for colleges and universities. A Report, University of Michigan, 1978.

DeLeon, P. A theory of policy termination. In J. May and A. Wildavsky (Eds.), The policy cycle in politics and public policy. Beverly Hills: Sage, 1978.

Hirschman, A. O. Exit, voice and loyalty: responses to decline in firms, organizations and states. Cambridge, Mass.: Harvard University Press, 1970.

Kaufman, H. The limits of organizational change. University: The University of Alabama Press, 1971.

Kotler, P., and Murphy, P. E. Strategic planning for higher education. The Journal of Higher Education, 1981, 52 (5). 
Melchiori, G. S. Coping with curricular change in academe. The AIR Professional File, No. 9, 1981.

Melchiori, G. S. Patterns of program discontinuance: a comparative analysis of state agency procedures for initiating and implementing the discontinuance of academic programs. Research Report, University of Michigan, Ann Arbor, 1980.

Peckham, H. H. The making of the University of Michigan. Ann Arbor: University of Michigan Press, 1967.

Riley, G. L., and Baldridge, V. J. Governing academic organizations. Berkeley, Calif.: McCutchan Publishing Company, 1977.

Received November $16,1981$. 